\title{
HUBUNGAN SENAM DIABETES TERHADAP KADAR GULA DARAH PUASA DAN 2 JAM POST PRANDIAL PASIEN DM TYPE 2
}

\author{
Achmad Hanif', Irma Suswati ${ }^{2}$, Dwi Nurwulan Pravitasari ${ }^{3}$ \\ Fakultas Kedokteran, Universitas Muhammadiyah Malang \\ J1. Bendungan Sutami 188 A Malang, 65145 \\ Email : arsenicarsenal@gmail.com
}

\begin{abstract}
ABSTRAK
Diabetes Mellitus type 2, merupakan salah satu keluhan umum yang sering dialami oleh pasien berumur diatas 45 tahun. Indonesia sendiri merupakan negara ke 4 paling banyak terkena kasus Diabetes Mellitus. Hal tersebut dapat terjadi karena pola makan yang tidak terjaga,olahraga yang kurang,dan lifestyle yang tidak sesuai. Senam diabetes merupakan langkah awal dalam mengatasi Diabetes MellitusTujuan: Untuk mengetahui hubungan antara senam diabetes terhadap kadar gula darah puasa dan 2 jam post prandial Metode: Penelitian ini menggunakan model observasi analitik dengan desain cohort dilakukan di Puskesmas Kendal Kerepterhadap 52 sampel pasien yang sesuai dengan kriteria inklusi dan eksklusi dengan pengambilan sampel secara purposive sampling. Analisis data menggunakan Wilcoxon.Hasil penelitian dan diskusi: Hasil analisis dengan korelasi Wilcoxon menunjukkan bahwa terdapat hubungan yang signifikan antara senam diabetes terhadap kadar gula darah puasa dan 2 jam post prandial $(\mathrm{p}=0,000)$ yang berarti senam merupakan salah satu faktor yang dapat menurunkan kadar gula darah puasa dan 2 jam post prandial.Kesimpulan: Terdapat hubungan yang signifikan antara senam diabetes terhadap kadar gula darah puasa dan 2 jam post prandial
\end{abstract}

Kata Kunci : Gula darah puasa,Gula darah 2 jam post prandial,Senam diabetes.

\section{ABSTRACT}

Diabetes Mellitus type 2, is one common complaint often experienced by patients aged over 45 years. Indonesia itself its the 4th largest country that affected by Diabetes Mellitus. This can be happen because of an unbealthy diet, lack of exercise, and an unsuitable lifestyle. Diabetic Exercise is the first step to overcome Diabetes Mellitus

Objective: To know the relationship between diabetic exercise to fasting blood sugar and 2 bours post prandial blood sugar Method: This research used analytic observation model with cohort design at Kendal Kerep Community Health Center toward 52 patient, according to inclusion criteria with purposive sampling.Wilcoxon is used for analyting data.Results and discussion: The result in correlation analysis showed that there was a significant relationship between Diabetic Exercise on fasting blood sugar and 2 hours post prandial $(p=0,000)$ that means diabetic exercise is one of the factors that can decrease fasting blood sugar and 2 hours post prandial blood sugar Conclusion: There is a significant relationship between diabetic exercise to fasting glucose and 2 hours post prandial

Keywords : Fasting Blood Sugar, 2 hours post prandial Blood Sugar, Diabetic Exercise. 


\section{PENDAHULUAN}

Diabetes Mellitus (DM) merupakan sekelompok kelainan heterogen yang ditandai oleh kenaikan kadar glukosa dalam darah atau hiperglikemia (Suyono, 2006). DM adalah penyakit metabolik akibat dari kurangnya insulin efektif baik oleh karena adanya disfungsi sel beta pankreas atau ambilan glukosa perifer atau keduanya pada DM tipe 2 atau kurangnya insulin absolut pada DM tipe 1 dengan tanda tanda hiperglikemia dan glukosuria, disertai gejala klinis akut (poliuria, polidipsia, penurunan berat badan) dan ataupun gejala kronik atau kadang-kadang tanpa gejala (Askandar, 2015). DM dapat diklasifikasikan berdasarkan penyebab, perjalanan klinik, dan terapi, yaitu DM tipe 1, DM tipe 2, DM gestasional dan tipe tertentu yang berhubungan dengan keadaan lainnya (Gustaviani, 2006).

Berdasarkan survei yang dilakukan oleh Badan Penelitian dan Pengembangan Kesehatan Kementrian Kesehatan RI pada tahun 2013 dalam laporan Hasil Riset Kesehatan Dasar didapatkan bahwa prevalensi diabetes di Indonesia mengalami peningkatan dari tahun 2007 per 1000 penduduk yaitu 2,1\% di tahun 2013, angka tersebut lebih tinggi dibanding dengan tahun 2007 yaitu 1,1\%. Di Indonesia sendiri diperkirakan bahwa pada tahun 2030 prevalensi DM mencapai 21,3 juta orang. Menurut penelitian epidemiologi yang dilaksanakan di Indonesia, jumlah penderita DM diatas umur 14 tahun di daerah Jawa Timur mencapai 28.885.895 (Riskesdas, 2013).

Sampai saat ini kriteria diabetes ditetapkan berdasarkan kadar glukosa darah, yaitu GDP (gula darah puasa) e"126 mg/dL dan G2PP (gula darah 2 Jam post prandrial) e" $200 \mathrm{mg} / \mathrm{dL}$ dan spektrum kadar GDP (gula darah puasa) 100-125 mg/dL dan G2PP (gula darah 2 Jam post prandrial) 140$199 \mathrm{mg} / \mathrm{dl}$ merupakan prediabetes, dimana komplikasi mikrovaskuler dan makrovaskuler seperti pada diabetes telah didapatkan dalam tingkat tertentu (American Diabetes Association, 2014).

DM adalah penyakit kronis yang menyebabkan morbiditas dan mortalitas utama, seperti halnya penyakit kronis lainnya. Pengontrolan gula darah merupakan tujuan utama dari berbagai penatalaksanaan yang dilakukan oleh penderita DM. Hal ini bisa dicapai dengan melakukan 4 pilar pengendalian DM, yaitu edukasi, pengaturan makanan, olahraga, dan obat (Novitasari, 2012). Olahraga merupakan upaya awal dalam mencegah, mengontrol, dan mengatasi diabetes. Salah satu program yang dicanangkan BPJS Kesehatan adalah PROLANIS (Program Pengelolaan Penyakit
Kronis). Salah satu bagian dari PROLANIS adalah senam diabetes yang diperuntukkan untuk penyandang diabetes (Panduan Prolanis, 2013). Senam diabetes sampai dengan bulan Agustus tahun 2015 telah dilaksanakan sebanyak 30.723 kegiatan (BPJS, 2015). Salah satu contoh keberhasilan PROLANIS bisa dilihat dari Puskesmas Padimas, di puskesmas tersebut terjadi peningkatan jumlah anggota PROLANIS, dari jumlah awal anggota sebanyak 80 orang meningkat menjadi 238 orang. Hal ini mengindikasikan kesadaran penyandang DM untuk mengelola dan mengendalikan penyakitnya semakin meningkat (BPJS, 2015).

Berdasarkan latar belakang tersebut, penulis tertarik untuk mengambil judul "Hubungan senam diabetes terhadap kadar gula darah puasa dan 2 jam post prandial pasien (DM) type 2".

\section{METODE}

\section{Desain Penelitian}

Desain penelitian ini adalah studi Analytical Komparatif dengan pendekatan Cohort, yang diambil dari catatan medik pasien Puskesmas Kendal Karep Malang.

\section{Seleksi Sampel Penelitian}

Populasi Sampel dalam penelitian ini adalah data rekam medik pasien DM type 2 yang terdaftar Prolanis di Puskesmas Kendal Karep yang memenuhi kriteria inklusi dan eksklusi

\section{Prosedur Penelitian}

Data didapatkan dari Puskesmas Kendal Karep Malang dengan jumlah penderita DM type 2 yang mengikuti program senam diabetes sebanyak 52. Pengambilan sampel dengan metode purposive sampling yaitu teknik penetapan sampel dengan cara memilih sampel diantara populasi sesuai dengan tujuan / masalah dalam penelitian ) dengan cara menetapkan kriteria inklusi dan eksklusi kemudian data diolah oleh SPSS. 


\section{HASIL DAN PEMBAHASAN}

Dari hasil pemeriksaan didapatkan hasil seperti tabel di bawah.

Tabel 5.1.4 Kadar gula darah puasa dan 2 jam post prandial sebelum senam

\begin{tabular}{|c|c|c|c|c|}
\hline & GDP & $\%$ & G2PP & $\%$ \\
\hline Tinggi & 52 & 100 & 52 & 100 \\
\hline Terganggu & 0 & 0 & 0 & 0 \\
\hline Normal & 0 & 0 & 0 & 0 \\
\hline Jumlah & 52 & 100 & 52 & 100 \\
\hline
\end{tabular}

Sumber : Data Primer, 2017

Berdasarkan tabel 5.1.4 data yang diperoleh dari 52 pasien penderita DM type 2 yang sesuai dengan kriteria inklusi diketahui bahwa jumlah penderita diabetes sebelum melakukan senam yang memiliki kadar gula darah puasa dan kadar gula darah 2 jam post prandial berkategori tinggi sejumlah 52 pasien $(100 \%)$

Tabel 5.1.5 Kadar gula darah puasa dan 2 jam post prandial sesudah senam

\begin{tabular}{|c|c|c|c|c|}
\hline & \multicolumn{2}{|c|}{ GDP } & \multicolumn{2}{|c|}{ G2PP $\%$} \\
\hline Tinggi & 4 & 7,6 & 4 & 7,6 \\
\hline Terganggu & 11 & 21,1 & 11 & 21,1 \\
\hline Normal & 37 & 71,3 & 37 & 71,3 \\
\hline Jumlah & 52 & 100 & 52 & 100 \\
\hline
\end{tabular}

Sumber : Data Primer, 2017

Berdasarkan tabel 5.1.5 data yang diperoleh dari 52 pasien penderita DM type 2 yang sesuai dengan kriteria inklusi diketahui bahwa jumlah penderita diabetes setelah melakukan senam yang memiliki kadar gula darah puasa dan 2 jam post prandial

berkategori tinggi sejumlah 4 orang $(7,6 \%)$ kemudian kategori terganggu 11 pasien $(21,1 \%)$ dan kategori normal berjumlah 37 pasien $(71,3 \%)$.

\subsection{Hubungan Antara Kadar Gula Darah Dengan Senam Diabetes}

Untuk mengetahui korelasi antara kadar gula darah puasa dan 2 jam post prandial dengan senam diabetes maka dilakukan tabulasi silang dan didapatkan data seperti pada tabel di bawah ini.
Tabel 5.2.1 Tabulasi silang gula darah puasa setelah 2 bulan kegiatan senam

\begin{tabular}{|c|c|c|c|c|c|}
\hline & \multicolumn{4}{|c|}{ GDP post } \\
\hline & & Tinggi & $\begin{array}{c}\text { Tergang } \\
\text { gu }\end{array}$ & Normal & Total \\
\hline \multirow{3}{*}{$\begin{array}{c}\text { GDP } \\
\text { pre }\end{array}$} & Tinggi & $\begin{array}{c}4 \\
(7,6 \%)\end{array}$ & $\begin{array}{c}11 \\
(21 \%)\end{array}$ & $\begin{array}{c}37 \\
(71 \%)\end{array}$ & \\
\hline & Terganggu & $f$ & $f$ & $f$ & \\
\hline & Normal & $f$ & $f$ & $f$ & \\
\hline
\end{tabular}

Sumber : Data Primer, 2017

Berdasarkan tabel 5.2.1 diperoleh informasi bahwa semua responden sebelum senam memiliki gula darah puasa kategori tinggi. Setelah mengikuti senam sebanyak 37 responden memiliki gula darah puasa normal,11 responden kategori terganggu, dan sisanya 4 responden tetap tinggi

Tabel 5.2.2 Tabulasi silang gula darah 2 jam post prandial setelah 2 bulan kegiatan senam

\begin{tabular}{|c|c|c|c|c|c|}
\hline & \multicolumn{4}{|c|}{ Dgtt Jalc } \\
\hline & & Tinggi & $\begin{array}{c}\text { Tergang } \\
\mathrm{gu}\end{array}$ & Normal & Total \\
\hline \multirow{3}{*}{ G2PP pre } & Tinggi & $4(7,6 \%)$ & $\begin{array}{c}11 \\
(21 \%)\end{array}$ & $\begin{array}{c}37 \\
(71 \%)\end{array}$ & $\begin{array}{c}52 \\
(100 \%)\end{array}$ \\
\hline & Terganggu & t & t & $t$ & \\
\hline & Normal & $f$ & $t$ & $t$ & \\
\hline
\end{tabular}

Sumber : Data Primer, 2017

Berdasarkan tabel 5.2.2 diperoleh informasi bahwa semua responden sebelum senam memiliki gula darah 2 jam post prandial kategori tinggi. Setelah mengikuti senam sebanyak 37 responden memiliki gula darah 2 jam post prandial kategori normal, 11 responden kategori terganggu dan sisanya 4 responden tetap tinggi

Untuk mengetahui korelasi antara senam diabetes terhadap kadar gula darah puasa dan 2 jam post-prandial, maka dilakukan uji analisis data Wilcoxon. Uji Wilcoxon dilakukan karena variabel penelitian berupa variabel nominal dan ordinal. 
Tabel 5.3 Tabel Uji Wilcoxon

\begin{tabular}{|c|c|c|c|c|}
\hline & & $\mathrm{N}$ & Sig & Keterangan \\
\hline \multirow{4}{*}{$\begin{array}{l}\text { GDP } \\
\text { post- } \\
\text { pre }\end{array}$} & $\begin{array}{l}\text { Negatif } \\
\text { Rank }\end{array}$ & 48 & \multirow[t]{4}{*}{0,000} & \multirow{4}{*}{$\begin{array}{l}\text { Terdapat } \\
\text { perbedaan kadar } \\
\text { gula darah puasa } \\
\text { sebelum dan } \\
\text { sesudah } \\
\text { melakukan } \\
\text { senam } \\
\end{array}$} \\
\hline & $\begin{array}{l}\text { Positif } \\
\text { Rank }\end{array}$ & 0 & & \\
\hline & Ties & 4 & & \\
\hline & Total & 52 & & \\
\hline \multirow{4}{*}{$\begin{array}{l}\text { G2PP } \\
\text { post- } \\
\text { pre }\end{array}$} & $\begin{array}{l}\text { Negatif } \\
\text { Rank }\end{array}$ & 48 & \multirow[t]{4}{*}{0,000} & \multirow{4}{*}{$\begin{array}{l}\text { Terdapat } \\
\text { perbedaan kadar } \\
\text { gula darah } 2 \text { jam } \\
\text { post prandial } \\
\text { sebelum dan } \\
\text { sesudah } \\
\text { melakukan } \\
\text { senam }\end{array}$} \\
\hline & $\begin{array}{l}\text { Positif } \\
\text { Rank }\end{array}$ & 0 & & \\
\hline & Ties & 4 & & \\
\hline & Total & 52 & & \\
\hline
\end{tabular}

Sumber : Data Primer, 2017

Tabel 5.3 menunjukkan perbandingan gula darah puasa dan gula darah 2 jam post prandial sebelum dan sesudah melakukan senam selama 2 bulan. Terdapat 48 sampel mengalami penurunan kadar gula darah puasa dan 2 jam post prandial dan terdapat 4 sampel mengalami hasil yang tetap. Bagian test statistik menunjukkan uji hasil Wilcoxon $(p=0,000)$, karena nilai $p<0,05$ secara statistik maka mempunyai arti bahwa terdapat perbedaan yang bermakna antara kadar gula darah puasa dan 2 jam post prandial sebelum mengikuti senam dan setelah mengikuti senam diabetes.

\section{KESIMPULAN}

Berdasarkan hasil penelitian dapat ditarik kesimpulan sebagai berikut:

a. Ada hubungan yang bermakna antara senam diabetes dengan kadar gula darah puasa dan 2 jam post prandial pada pasien DM type 2,hasil analisis wilcoxon menunjukkan terdapat hubungan yang signifikan $\mathrm{p}=0,000(\mathrm{p}<0,05)$

b. Kadar gula darah puasa dan 2 jam post prandial pada pasien DM type 2 sebelum senam termasuk dalam kategori tinggi

c. Kadar gula darah puasa dan 2 jam post prandial pada pasien DM type 2 sesudah senam sebagian besar $(71 \%)$ termasuk dalam kategori normal

\section{DAFTAR PUSTAKA}

Aathira R.JJain V., 2014,Advances in management of type 1 diabetes mellitus. World J Diabetes, vol. 5, pp 689-696.

American Diabetes Association (ADA), 2011, Diagnosis, Classification and How to Overcome Diabetes Mellitus, diakses pada 12 Januari 2014 dari: www.care.diabetesjournals.org/ content/34/Supplement_1/S62.full

Anisah, 2013, Perbedaan Kadar Gula Darah Sebelum dan Sesudah Senam Diabetes pada Pasien DM Tipe 2 http:// repository.uinjkt.ac.id/dspace/bitstream/ $123456789 / 28938 / 1 /$ ANISAH\%20KHOIRUL\%20U-FKIK.pdf

Anugrah, 2013 ,Hubungan Obesitas,Olahraga, dan Kebiasaan Merokok dengan penyakit Diabetes Melitus Tipe II pada Pasien Rawat Jalan Rumah Sakit Dr. Wahidin Sudirohusodo Makassar.Jurnal Ilmiah Kesehatan. Vol 1. No 6. Jan. pp 1-8

Arisman, 2011, Obesitas Diabetes Mellitus \& Dislipidemia,Jakarta: Penerbit Buku Kedokteran EGC, vol. 1, pp 56.

Askandar Tjokroprawiro, dkk., 2015, Buku Ajar Ilmu Penyakit Dalam edisi II, Surabaya: FK UNAIR, pp 100.

Badan Penelitian dan Pengembangan Kesehatan Kementerian Kesehatan RI, 2013, Riset Kesehatan Dasar 2013 (RISKESDAS 2013), Jakarta: Depkes RI. Available from: http:// depkes.go.id/downloads/riskesdas2013/ Hasil\%20Riskesdas\%202013.pdf

Bays, 2007 ,The relationship of body mass index to diabetes mellitus, bypertension and dyslipidaemia: comparison of data from two national surveyshttps:/ /www.ncbi.nlm.nih.gov/pmc/articles/ PMC1890993/

Bella, 2016, Faktor-Faktor yang Berhubungan dengan Kejadian Diabetes Melitus Tipe II http://jukeunila.com/wp-content/uploads/ 2016/04/5.2_Bella_Yanita_done.pdf

Bennett, P., 2008, Epidemiology of Type 2 Diabetes Millitus, in Le Roith et al., Diabetes Millitus a Fundamental and Clinical Text, Philadelphia: Lippincott William \& Wilkin, vol. 1, pp 522

Boule' NG, Haddad E, Kenny GP, Wells GA, Sigal R. et al., 2001, Effects of Structured Exercise Interventions on Glycemic Control and 
Body Weight in Type 2 Diabetes, Diabetes Care, pp 97

BPJS, 2013, Panduan PROLANIS,http://bpjskesehatan.go.id/bpjs/dmdocuments/06PROLANIS.pdf

Cheng, D., 2007, Prevalence, predisposition and prevention of type II diabetes, Department of Obesity and Metabolic Research, USA, pp 34

Dimas, 2013 , Kepatuhan Penderita Diabetes Mellitus dalam Menjalani Terapi Olahraga dan Diet http://lib.unnes.ac.id/17487/1/ 1550408022.pdf

Dinar, 2008, Pola Penggunaan Obat Hipoglikemik Oral pada Pasien Diabetes Mellitus Tipe 2 di Instalasi Rawat Jalan RSUD DR Moewardi Surakarta http://eprints.ums.ac.id/ 5233/1/K100050250.pdf

Departemen Kesehatan Republik Indonesia, 2008, Pedoman Teknis Penemuan dan Tatalaksan Penyakit Diabetes Mellitus Cetakan II pp 27

Gustaviani R, 2007, Diagnosis dan Klasifikasi Diabetes Melitus, Buku Ajar Ilmu Penyakit Dalam edisi IV, Jakarta: FK UI, pp 77

Hayley, 2013,AMPK and Exercise: Glucose Uptake and Insulin Sensitivity https:// www.ncbi.nlm.nih.gov/pmc/articles / PMC3579147/

Huang, I., 2015, Pancreatic Hormones and Diabetes Mellitus, German MS, Germany, vol. 17, pp 136

Iin Mutmainah, 2014, Hubungan Kadar Gula Darah dengan Hipertensi pada Pasien Diabetes Mellitus Tipe 2 di RS Karanganyar http:// eprints.ums.ac.id/24357/14/ 2_NASKAH_PUBLIKASI.pdf

Lina, 2010, Pengaruh Senam Aerobik terhadap Kadar Glukosa Darah Pasien DM type 2 di RSU Unit Swadana Daerah Kabupaten Sumedang http://www.stikesayani.ac.id/ publikasi/e-journal/filesx/2010/201008/ 201008-001.pdf

Miftahul, 2013, Hubungan Indeks Massa Tubuh (IMT) Dengan Kadar Gula Darah Penderita Diabetes Mellitus (DM) Tipe 2 Rawat Jalan Di RS Tugurejo Semarang http:// jurnal.unimus.ac.id/index.php/jgizi/article/ viewFile/752/806

Mihardja L., Delima T., Siswoyo H., et al., 2009, Prevalence and determinants of diabetes mellitus and impaired glucoce tolerance in Indonesia, Acta Med Indonesia, vol. 4, pp 169-174.
Novitasari, R., 2012, Diabetes Melitus Medical Book, Yogyakarta: Nuha Medika, pp 34-37

Pavankumar Patel, 2013, Body Fat Distribution and Insulin Resistance https:// www.ncbi.nlm.nih.gov/pmc/articles / PMC3725490/

Perkumpulan Endokrinologi Indonesia (PERKENI), 2006, Konsensus Pengelolaan Diabetes Melitus di Indonesia, Jakarta, pp 98101

Pinel, J., 2012, Biopsikologi, Yogyakarta: Pustaka Pelajar, vol. 2, pp 77-80

Qurratuaeni,2009, Faktor-Faktor yang berhubungan dengan Terkendalinya Kadar Gula Darah Pada Pasien DM Type 2 di RSUP Fatmawati Jakarta http://repository.uinjkt.ac.id/dspace/ bitstream/123456789/597/1/92496QURRATUAENI-FKIK.pdf

Reni , 2014, Hubungan Kepatuhan Diit dengan Kadar Gula Darah Pada Pasien DM tipe 2 http:// eprints.ums.ac.id/28060/17/ NASKAH_PUBLIKASI.pdf

Snehalatha, Chamukuttan dan Ramachandran, Ambady, 2009, Diabetes melitus dalam gizi kesehatan masyarakat, Editor : Michael J Gibney, , Penerbit Buku Kedokteran EGC, Jakarta, vol. 1, pp 67-69

Soegondo S., Subekti I., 2002, Konsensus Pengelolaan diabetes mellitus tipe 2 di Indonesia, PB Perkeni, pp 56-60

Sudaryanto,2014 Hubungan antara Olabraga dengan diabetes mellitus type $2 \mathrm{http}: / /$ publikasiilmiah.unwahas.ac.id/index.php/ PROSIDING_SNST_FT/article/view/ $985 / 1098$

Sugiyono, 2009,Statistik UntukPenelitian,Bandung: ALFABETA, vol. 2, pp 34-35

Suhartono T, 2009, Diabetik Neuropati,Semarang: Badan Penerbit Universitas Diponegoro, pp 15-20.

Suhartono T., 2004, Naskah Lengkap PB Persadia. Simposium Diabetes Melitus untukDokter dan Diabetisi, Semarang: Universitas Diponegoro, pp 25-31.

Suyanto, 2009, Peran Senam Diabetes bagi Penderita Diabetes Mellitus http://staffnew.uny.ac.id/ upload/131808680/penelitian/1. Peran+Senam+Diabetes + Indonesia + bagi + Penderita + Diabetes + Mellitus + $(+$ Medikora, +$)$ ktober+2009).pdf 


\section{VOLUME 12 NOMOR 1 JUNI 2016}

Suyono S, 2006, Diabetes Melitus di Indonesia, Buku ajar Ilmu Penyakit Dalam, Jakarta: Pusat penerbitan Ilmu Penyakit dalam FK UI, vol. 4, pp 80-85

Thompson, Janice; Manore, Melinda; Sheeshka, Judy (2010), Nutrition a functional approach, Toronto, Ontaria: Pearson Canada, pp. 141144

Utomo, M., Mahalul O., Dina A., N,A., 2012, Pengarub Senam Terhadap Kadar Gula Darah Penderita Diabetes, Unnes Journal of Public Health,diakses http://journal.unnes.ac.id/sju/ index.php/hjp. diakses 15 Juli 2013

World Health Organization, 2011, Noncommunicable disease country profiles 2011 WHO global report, Ganeva: World Health Organization, pp 4-5.

Yunir E., Soebardi S., 2009, Terapi non farmakologis pada diabetes mellitus, dalam Sudoyo AW, dkk (eds), Buku Ajar Ilmu Penyakit Dalam jilid III, Pusat Penerbitan Departemen Ilmu Penyakit Dalam FKUI, Jakarta, vol. 4, pp $78-80$ 